\title{
TOWARDS A ‘BENCHMARKING RASTER': A SELECTION OF INDICATORS TO MEASURE AND ASSESS POLICIES FOR CULTURAL AND CREATIVE INDUSTRIES
}

\author{
Valentina Montalto*, Maria Iglesias ${ }^{* *}$, PhilipPe Kern ${ }^{* * *}$ \\ KEA European Affairs, Brussels
}

Manuscript received: January 20, 2012

Revised version:November 7, 2012

\begin{abstract}
Montalto V., Iglesias M., Kern P., 2012. Towards a 'benchmarking raster': A selection of indicators to measure and assess policies for cultural and creative industries. Quaestiones Geographicae 31(4), Bogucki Wydawnictwo Naukowe, Poznań, pp. 33-42. 3 figs. DOI 10.2478/v10117-012-0033-5, ISSN 0137-477X.

AвSTRACT. Research has devoted considerable attention to the contribution of cultural and creative industries (CCIs) to economic growth and innovation. Measuring and evaluative tools have played an increasingly important role in meeting the demand for the accountability of public money supporting this sector. Nevertheless, creativity remains an elusive subject for policy-makers. One of the major obstacles in adopting CCI policies is the difficulty in apprehending the value of support actions for cultural and creative enterprises. The present research is a first attempt to create a harmonised and simple set of indicators (the 'benchmarking raster') to assess local policies targeting economic development of CCIs. It has been completed in the framework of the INTERREG-funded CREA.RE network with the aim to encourage the authorities of small and medium-sized cities and regions to further invest Structural Funds in CCIs. It is also expected to contribute to CCI-focused economic development strategies (or Smart Specialisation Strategies).
\end{abstract}

KEY WORDS: cultural and creative industries, evaluation, indicators, local support policies and measures, cities and regions

Valentina Montalto, Maria Iglesias, Philippe Kern, KEA European Affairs, 51 rue du Trône, 1050, Bruxelles, Belgium; email:vmontalto@keanet.eu.

\section{Introduction}

Recent research has devoted considerable attention to the economic role of cultural and creative industries (CCIs) in our societies. CCIs have been analysed, first, as the main contributor to development and growth (KEA 2006, Throsby 2001, UNCTAD 2008 and 2010, among others) and, lately, also as a leading edge of innovation and change for 'non-creative' sectors within the knowledge economy (KEA 2009, Bakhshi et al. 2008, Pratt \& Jeffcutt 2009).

Richard Florida's work (Florida 2002, 2006, Gertler et al. 2002) has in particular drawn attention to the economic dimension of cultural and creative resources and investments at the local

\footnotetext{
Research consultant, KEA European Affairs, vmontalto@keanet.eu

** Head of Studies and Research, KEA European Affairs, miglesias@keanet.eu

*** Managing Director, KEA European Affairs, pkern@keanet.eu
} 
level. Florida has suggested interesting correlations between cultural factors of a territory and the creative economy. Cities and regions are identified as suitable attractors of creative talents to boost innovation and competitiveness. Although his conclusions are not always entirely shared (Kotkin 2005, Rushton 2006) or, according to others, not empirically tested (Malanga 2004, McCann 2007, Sands \& Reese 2008), he has inspired several regional and local policy-makers across the world convinced of the need to support cultural and creative companies for a successful shift towards a de-industrialised economy.

Nevertheless, creativity remains an elusive subject for policy-makers. One of the major obstacles in adopting CCI policies is the difficulty in apprehending the value of support actions for cultural and creative enterprises. Cultural statistics are rarely available. Public resources are often insufficient to carry out appropriate monitoring and assessment exercises. Policy-makers and officials dealing with culture often lack a 'culture of evaluation'.

The demand for the accountability of public money has been rising across the world. Measuring and evaluative tools have played an increasingly important role in meeting such demand, also in the fields of arts and culture. Since the 1970s, research on cultural indicators has been an active part of cultural policy research (Gouiedo 1993). Much work has been done on improving cultural policy-related statistics - the cultural statistics programmes of UNESCO (Lievesley 2002), Eurostat (European Commission 2000), IFACCA (2002, 2004b), Allin (2000), Glade (2003), and Manninen (2002) - as well as 'cultural indicators', especially at the international level (World Bank 2004', United Nations², among others). Quantitative and qualitative indicators are expected to help understand, evaluate and communicate the importance and effectiveness of culture-related policies and programmes.

As a consequence, even though the use of indicators is not widespread in cultural policy, thinking on cultural indicators is now well developed. Nevertheless, indicators measuring

\footnotetext{
1 http://www.worldbank.org/data/wdi2004/index. htm

2 http://unstats.un.org/unsd/demographic/social/ default.htm
}

the results of policies intended to support the economic growth of cultural and creative industries are still at an initial stage. Apart from some experiences linked to the assessment of big local cultural events targeting also CCIs (e.g. Liverpool 2008, the European Capital of Culture), indicators are little used by policy-makers dealing with CCIs from an economic perspective. CCI policies are too recent for their impacts to be fully assessed yet, as noted by Foord (2008) and confirmed by the experts consulted ${ }^{3}$. Furthermore, the international frameworks of indicators are difficult to adapt for specific policy purposes, "as the proposed indicators are not fully developed to an operational level" (IFACCA 2004a).

The present work is relevant to the academic community as well as to policy-makers. It is a first attempt to create a harmonised set of indicators (the 'benchmarking raster') to be applied at the operational level to assess local policies targeting economic development of CCIs. It contributes to the existing literature by presenting the results of an empirical research that has established and tested a benchmarking raster in the framework of the INTERREGfunded CREA.RE network ${ }^{4}$. It takes into account the variety of existing support measures (from governance to single support actions such as training, classified in four categories) and develops indicators accordingly. Our research also answers the European Commission's (EC) call to develop "evidence-based policies" (EC 2010). The EC has also indicated CCIs as one of key sectors to invest in to develop Smart Specialisation Strategies, or development strategies based on key sectors for present and future development (Smart Specialisation Platform 2011). The benchmarking raster can help assess the policies to adopt within a smart strategy focusing on cultural and creative enterprises.

This paper is structured as follows: it first presents in detail the methodology we used in

Consultations were held in March-April 2011.

4 CREA.RE gathers 12 partners (small and mediumsized cities and regions) from ten Member States in Europe. Its aim is to raise the awareness of the importance of CCIs and therefore encourage local authorities to further invest EU regional funds, namely the Structural Funds, in this sector. 
our research; secondly, it presents the identified categories of policy support measures; thirdly, it introduces and explains the benchmarking raster (as validated by the CREA.RE members); fourthly, it underlines the 'pros' and 'cons' of the raster; finally it summarises the main findings of this exercise and suggests the scope for further research.

\section{Methodology}

The benchmarking raster was conceived as a user-friendly tool aimed at gathering data to assess the 'value for money' of support actions for CCIs, facilitating the design of evidence-based policies at the local level, thereby contributing to the CREA.RE objectives of stimulating local investment of EU funds in CCIs. These indicators are expected to provide useful information to help the European Commission and regions in Europe to decide on the allocation of EU Structural Funds to this sector.

Our methodology was based on a multimethod approach intended to enrich and crossvalidate our findings. We used a multiple-choice questionnaire and interviews to gather both qualitative and quantitative data on the existing support measures and current uses of indicators at city and regional levels.

We first identified the existing support measures (for CCIs, but also for other sectors and which could be applied to CCIs) based on desk research, and classified them under four categories of support. Secondly, we selected a number of good practices (15) as practical examples of support measures, which also allowed us to look at the use of indicators in local contexts (which we observed quite rarely).

The good practices were selected according to the following criteria:

- Provide promising and/or interesting elements in terms of coherence with local policy plans; management structure and stakeholders involved; and overall impacts;

- Respect geographical balance across Europe;

- Represent territories at different stages of development in CCI policies;
- Mainly focus on small and medium-sized areas (based on the EUROSTAT definition ${ }^{5}$ ).

At the same time, we compiled a list of indicators based on a literature review and in relation to the previously identified categories of support measures.

Culture experts were also consulted through questionnaires and interviews on the identified categories of support and indicators. They were mainly identified through the selection of the good practices.

In the end, five evaluation criteria, often used in policy evaluations (OECD 2010, EC 6 ) guided us in the final selection of indicators: relevance, effectiveness, efficiency, impact, and sustainability.

The benchmarking raster was validated by CREA.RE members after a six-month testing phase (May-November 2011). The KEA team improved and finalised the indicators on the basis of their comments. KEA added guidelines on how to implement the benchmarking raster, including examples on the kind of data to be collected and data sources to be consulted ${ }^{7}$. KEA thus answered the main concern of CREA.RE members to have a benchmarking raster which could realistically be applied in small administrations confronted for the first time with an evaluation of CCI policies.

\section{Typology of policy support measures}

The CCI policy support measures refer to any action launched at the local level which mobilises different types of resources and is financed by the public sector to achieve public policy objectives in the area of CCIs and economic development. These encompass measures benefiting not only creative entrepreneurs but also 'indirect ben-

\footnotetext{
Medium-sized cities - those that have a population of between 50,000 and 250,000 (EUROSTAT, http:/ / epp.eurostat.ec.europa.eu/cache/ITY_SDDS/en/ urb_esms.htm)

6 http://ec.europa.eu/europeaid/evaluation/methodology/methods/mth_ind_en.htm

7 For further information, see KEA's study "Towards a benchmarking raster: a selection of indicators to measure policies for CCIs" (forthcoming).
} 
eficiaries', such as financial organisations (e.g. banks, loan funds, investment funds), clusters/ networks, knowledge transfer structures in universities and public research organisations, or business incubators.

At present, various types of support measures exist for CCI development, either driven by local policy strategies/programmes ${ }^{8}$ or launched by private stakeholders and later supported by public authorities. These may be either CCIspecific or integrated in other policies intended to foster economic development, for instance of SMEs. Tailored support measures are preferable (Utrecht School of the Arts 2010) as they are supposed to take into account the specificities of CCIs, namely the difficulty of valuing intangible capital, the small size and difficult scalability, the uncertainty of demand, and linguistic fragmentation for content industries (KEA 2010).

Interesting exercises have been conducted to categorise policy support measures, especially in the field of innovation (Cunningham et al. 2008). Nevertheless, an 'official' categorisation of policy support measures for CCIs does not exist.

The first round of consultations carried out through a specific questionnaire disseminated among the CREA.RE members illustrated the growing importance of support policy measures to unleash CCI potential at the local level, with the following results: ${ }^{9}$

- The development of support policies and strategies for CCIs is essential for most CREA. $\mathrm{RE}$ cities and regions.

8 Examples across Europe and beyond include for instance: Creative Tampere Programme 2006-2011 (Finland), Vision on the Creative Economy 2007 (Rotterdam, The Netherlands), National Strategy for European Structural Funds 2007-2013 (Estonia), North Rhine-Westphalia - Objective 2 ERDF Programme (Germany), Baden-Württemberg - Objective 2 ERDF Programme (Germany), Culture and Space Action Programme 2007-2013 (The Netherlands), Vision Cultural Policy for Region Västra Götaland (Sweden), West Midlands Cultural Strategy 2001-2006 (UK), Manchester Cultural Strategy 2002-2012 (UK), City of Amsterdam's Arts Factory Policy - Art Factories Programme for 2008-2012 (The Netherlands), Create Denver (USA).

9 Results based on answers to a questionnaire sent to CREA.RE members in November 2010.
- Support policies are identified by most of them as the main reason why a city can be considered to be the most creative one.

- Various cities support CCIs as part of their economic development strategy. They include: Graz and Styria in Austria; Podravje in Slovenia; Berlin in Germany; Tampere in Finland; Gdynia in Poland; San Sebastián, Barcelona and Madrid in Spain; Milan, Rome and Turin in Italy; Limburg in The Netherlands; and Kortrijk in Belgium.

- In most cities, CCI policies are very recent with very different objectives: developing entrepreneurship, creating economic activities, exploiting cultural heritage, network talents, supporting cultural expression, improving cultural consumption, or developing urban regeneration.

- CREA.RE cities and regions consider that the main outcomes of a CCI policy should be:

a. developing entrepreneurship;

b. creating new economic activities and boosting innovation; and

c. generating employment.

The wide variety of the existing support measures (from comprehensive policies, specific actions ranging from the establishment of infrastructures to training services, to access to financial tools) requires the definition of a limited number of support categories. As all grouping exercises, this implies a simplification of the reality. However, at the same time, it makes the definition of indicators feasible in relation to a clarified picture of what exists. Policy support measures ${ }^{10}$ have been categorised by the following four areas.

1. Measures related to infrastructure and clustering/networking are aimed at supporting business establishment as well as synergies and collaboration between CCIs and other industries or among creative stakeholders. Fostering creativity requires the setting up of the right conditions to attract talents and creative resources. "It is easier to enhance creativity by changing conditions in the environment than by trying to make people think more creatively" (Csikszentmihalyi 1996: 24). The spa-

10 For more details, see KEA's study “Towards a benchmarking raster: a selection of indicators to measure policies for CCIs" (forthcoming). 
tial dimension and the interactions generated on a limited territory are crucial for creativity to emerge, but also to allow SMEs to scale up and reach larger markets (Porter 1998). Under this support category, we therefore refer to actions like the creation of physical or virtual infrastructure to attract and gather creative talents locally, the provision of technology tools and services, or the organisation of networking events. Local authorities have a key role to play in facilitating interactions in a defined area.

2. Measures related to skills, competences and entrepreneurship are aimed at supporting the development of business competences and skills as well as access to financial tools. At various stages of the life-cycle of a business, (creative) entrepreneurs require skills and competences to sustain their idea, develop commercial strategies, as well as financial sources. They require expert advice, for instance on technology, design, marketing or intellectual property issues (e.g. licensing or trademark registration). Access to finance is a key factor at an early stage but also at growth and development stage when the company wants to expand and reach new markets (KEA 2010). The European Commission's Green Paper on Cultural and Creative Industries refers to the CCIs' need for "increased capacity for experimenting and innovating, access to the right mix of skills, and access to funding" (EC 2010). This support category therefore includes training and advice services as well as the establishment of tools (e.g. venture capital funds) to ease access funding for creative businesses in a wide range of areas with a view to addressing their skills and financial needs (KEA 2010).

3. Incubation is a transversal form of support that combines complementary 'hard' (infrastructure) and 'soft' (networking and clustering, financing and skill development) support measures to back start-ups. "Business incubation process adds value by accelerating the start-up of new businesses and maximising their growth potential in a way that is more difficult for alternative SME support structures to achieve", as found out by a survey carried out by the Centre for Strategy and
Evaluation Services (CSES 2002) on behalf of the European Commission ${ }^{11}$. More specifically, a recent EC study indicates that "successful culture-based projects frequently combine investment in infrastructure with the development of a range of support initiatives both for cultural activities and for business aspects" (CSES 2010) These include services such as business advice and planning, the development of training and education provision, and support to ease access to finance.

4. Measures related to governance refer to the political, institutional and administrative framework built to set and implement CCI policies as well as support measures. Support for CCIs can indeed be integrated and mainstreamed across a wide range of distinct policy areas seen as essential to back the sector, including economic affairs, education, competition, innovation, regional development, and social and urban planning. This implies appropriate coordination among different stakeholders that can be created, for instance, through appropriate task forces, working groups, or CCI-dedicated and multidisciplinary public agencies.

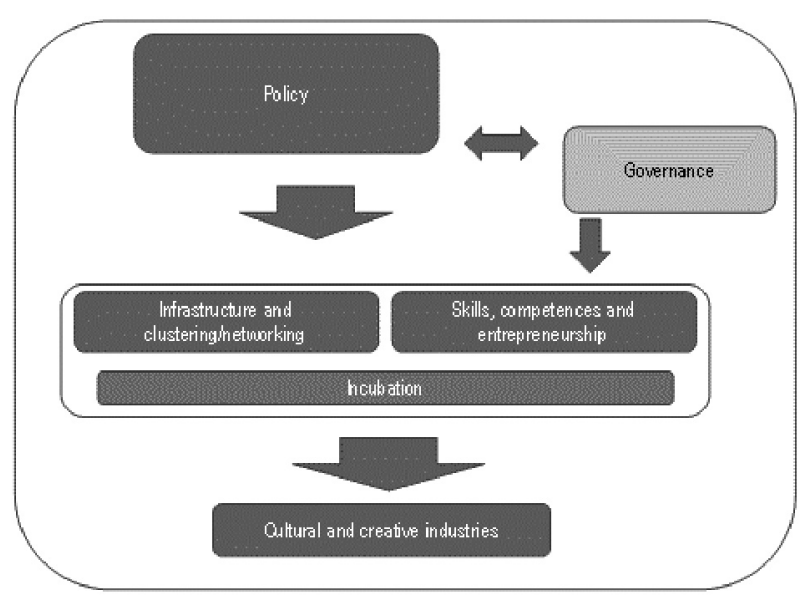

Fig. 1. Categories of policy support measures.

11 Incubators are flourishing in the CCI sector, especially (but not exclusively) in those areas that want to invest in the creative economy but lack a creative 'entrepreneurial infrastructure'. Only in Estonia, for instance, three creative incubators were funded in January 2010 as part of the Creative Industries Support Structures Development Programme (Estonian Ministry of Culture, 2010). An incubator not only directly supports cultural and creative businesses through a combination of support measures but, by gathering together creative entrepreneurs, it also contributes to creating an environment conducive to creativity. 


\section{The benchmarking raster}

\subsection{Indicators}

The benchmarking raster that follows is the one validated by the CREA.RE members during the testing phase. It takes into account the variety of the existing support measures and develops indicators according to their identified categories. The indicators are designed to measure the performance of CCI support measures at three levels: governance, single support actions, and combined support actions (notably incubation). In the raster we also distinguish key performance indicators that help assess the overall contribution of policies to the development of cultural and creative business.

In the raster we use both quantitative and qualitative indicators that operate as a set of interconnected and complementary variables, each of them providing data to evaluate the measure. Some of them are common to all the support measures (excluding governance), others are spe- cific to one or several of them, as certain support measures require particular types of assessments depending on their nature. Specific indicators are selected for governance, as this provides an overall support to CCI policies and support measures. Fig. 2 summarises our benchmark raster of 23 indicators that are classified as follows:

\section{A) Key overall performance indicators}

We propose three 'key performance' indicators to assess the overall contribution of support measures to the development of the economic potential of CCIs.

\section{B) Indicators for support measures (excluding governance)}

This series of indicators refers to management issues, the resources put into an initiative as well as the effects of the measure in terms of deliverables produced and direct beneficiaries (intermediate results). It helps to evaluate the overall performance of the measure. We propose in particular:

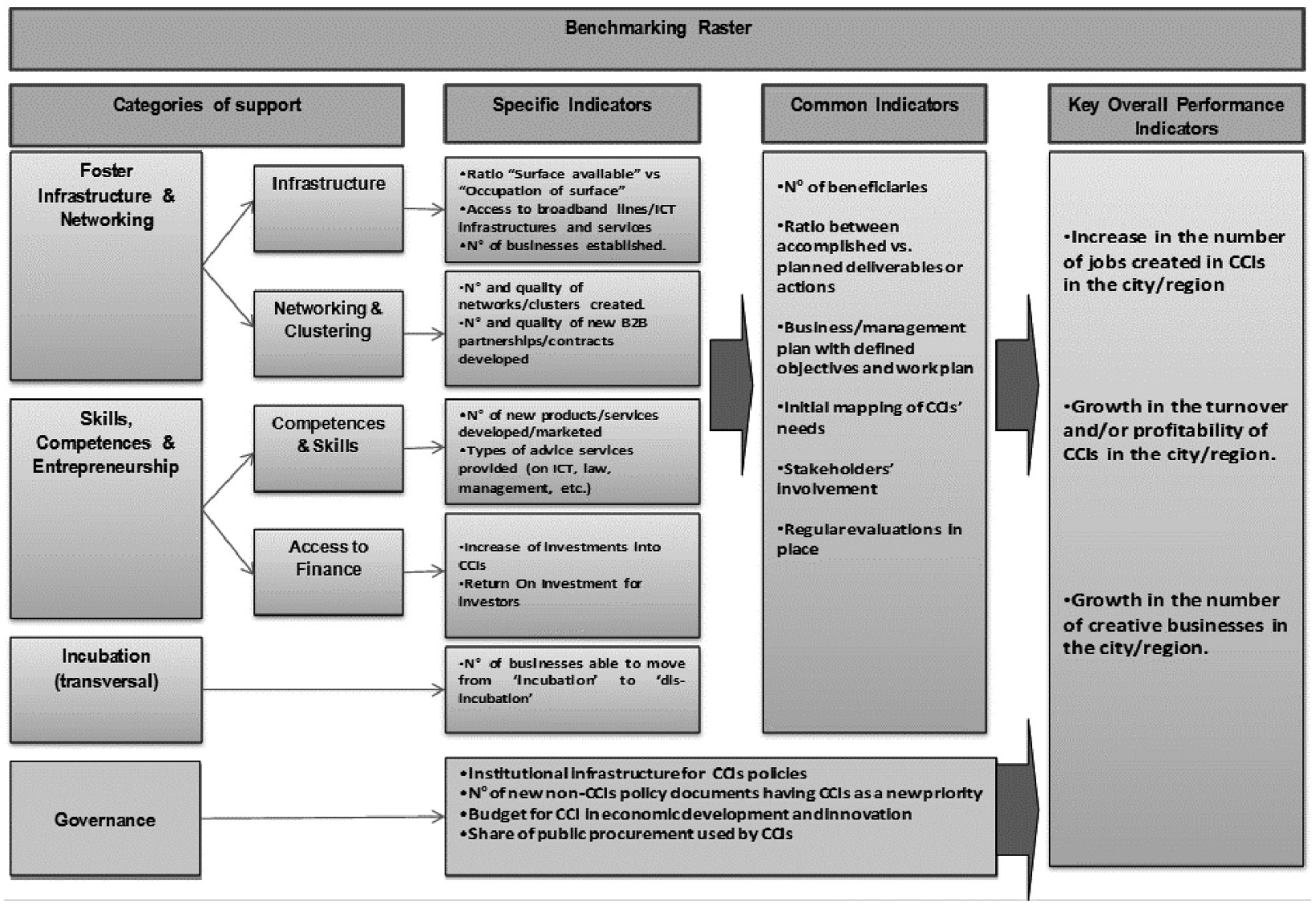

Fig. 2. The benchmarking raster. 
- six common indicators;

- five specific indicators related to support measures to foster infrastructure and networking;

- four specific indicators related to support measures for skills, competences and entrepreneurship; and

- one specific indicator related to the transversal support category for incubation schemes.

\section{C) Indicators for governance}

Four specific indicators have been specifically designed to assess governance in setting up and implementing policies for CCIs.

The indicators listed in the benchmarking raster have been defined taking into account the five evaluation criteria mentioned earlier, commonly used by decision-makers to evaluate the performance of support measures and programmes: effectiveness, efficiency, relevance, impact, and sustainability. They should inform policy authorities on the whole evaluation exercise. An example on how to connect evaluation criteria to indicators is provided below.
Regular evaluations contribute to the assessment of the measures in relation to the five evaluation criteria.

\subsection{Pros and cons}

The proposed benchmarking raster is the very first attempt to provide a tool, 'standardised' but open to adaptations, to perform an appropriate evaluation of CCI policies at the local level. The indicators can also support monitoring, influence behaviour and attitudes (for instance by building public confidence or attracting talented people and investments by showing the success of policies for CCIs), and stimulate learning and change in public administration (by showing which policies are more relevant and effective).

The use of indicators has nevertheless to face lack of evaluation culture, missing data or even of data collection methods, little experience/expertise within public administration in performing monitoring tasks, or resource constraints in assessing public policies.

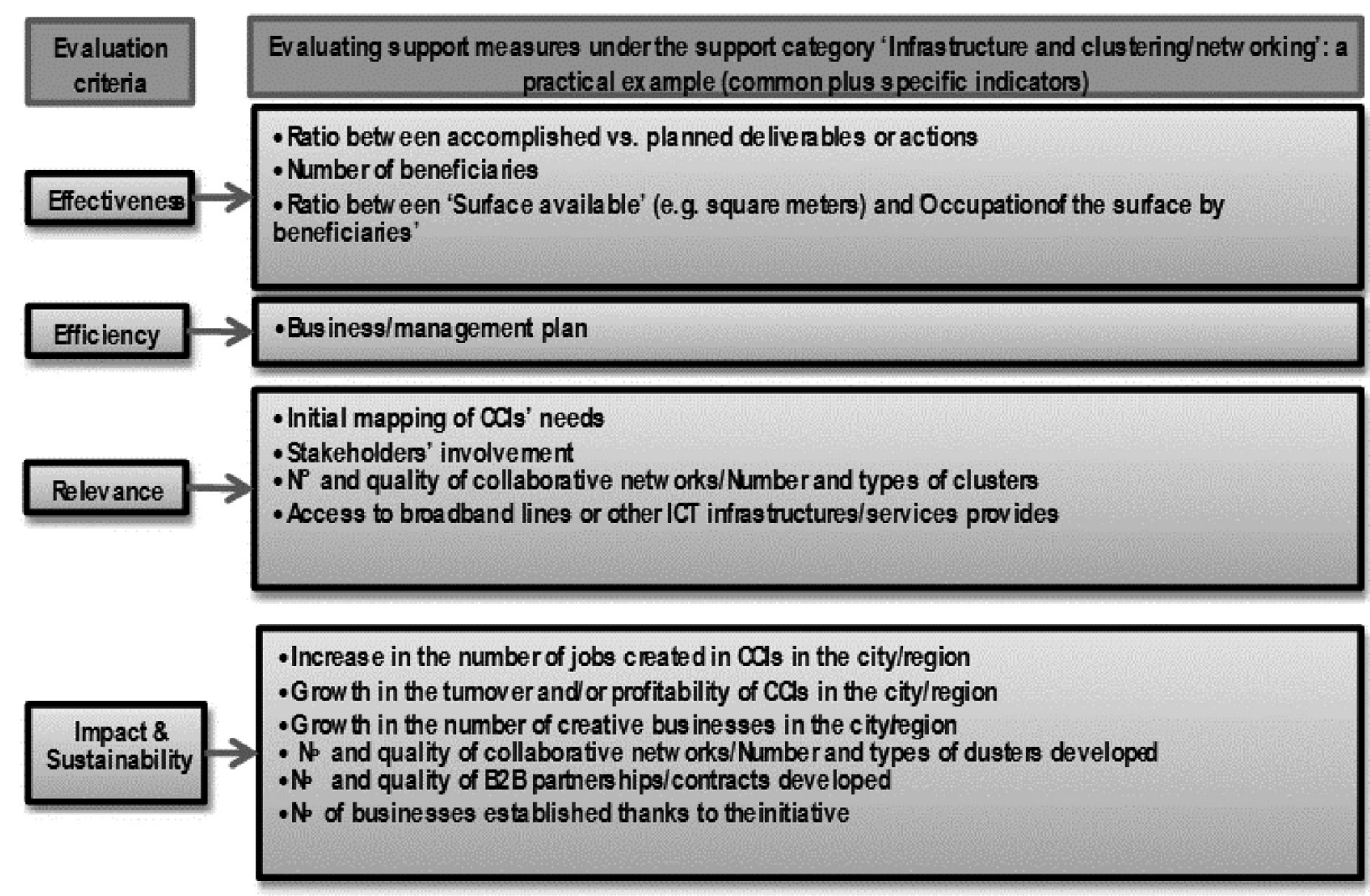

Fig. 3. Connecting indicators to evaluation criteria. 
The testing exercise confirmed the supposed advantages but also limits of (a practical application of) the benchmarking raster. The CREA.RE members found it useful especially as a first step to understanding how to plan monitoring and evaluation, and identify indicators possible to use. However, the recent set-up of local support measures, resource constraints (in terms of time and staff), lack of data as well as the governance model (notably lack of involvement of stakeholders and a specific distribution of competences related to CCIs in public administration) made it difficult, if not impossible, to determine the indicators using relevant information. Also, the testing phase had some limits in itself:

- limited time: the six-month testing phase was often considered too short to collect relevant data, also because data collection methods in most cases were not there;

- a restricted sample: the benchmarking was tested by only seven administrations, not all of them being in charge of CCIs but just of culture-related measures;

- incomplete information: very little information was provided by the CREA.RE partners, therefore, it was often difficult to understand what problem was encountered in the collection of data (missing data? non-applicability of the indicator?); and

- the first approach to economic evaluation: for many members, this was the first approach to evaluation and it proved difficult for them to understand the economic vocabulary used by the proposed indicators.

The testing exercise also confirmed that the benchmarking raster alone was not sufficient to assess public policies. The causal relationship is more complex than producing data and indicators, especially in that feedback mechanisms should be established to pass from data production to policy analysis (Bonet 2004). The indicators help to evaluate policies only if used in a context of a wider evaluation strategy.

\section{Conclusions}

While international matrixes of indicators are rarely usable at an operational level (IFACCA 2004b) and 'local' indicators "remain decentral- ised and highly project-specific" (Listening ... 2001), this paper contributes to the existing literature by providing a standardised benchmarking raster, empirically tested by the CREA.RE partners, for local policy-makers to measure policies for CCIs.

The main challenge was to find a reasonable trade-off for a reasonable number of indicators which could provide a sufficient amount of information to enable decision-making. The list is limited in number in order to avoid decision-makers being swamped with an excess of information. In several European regions, evaluations have shown that a few dozen indicators are enough to meet the information needs of the authorities running support measures (European Commission - Regional Policy ${ }^{12}$ ).

Nevertheless, the aim was also to provide a flexible instrument open to adaptations that reflect local specificities. We recommend policymakers to assess evaluation readiness, set up an evaluation strategy, methods and tools and, within that, 'shape' the benchmarking raster in relation to the specific local context and objectives $^{13}$ of the support measures. This means, for instance, defining targets against which the indicators will be measured, and introducing the process of regular data collection enabling the identification of changes and trends as well an assessment of the efficiency and durability of the measures adopted. The causal effect of a policy measure should also be assessed. Indicators mainly give information on the evolution but rarely give account of external factors linked to a positive environment. Indeed, the quality of support measures provided by public authorities cannot be seen as a clear pre-condition for the establishment of successful creative ecology.

12 http://ec.europa.eu/regional_policy/sources/ docgener/evaluation/ evalsed/guide/ methods_techniques/ indicators/ selection_en.htm

13 For instance, in those cities or regions where the CCI sector is young, measures will aim at increasing the number of creative businesses and it would therefore be appropriate to assess their impact by taking into account the number of new companies created. However, in more saturated markets, an increase in turnover or profitability would be a more fitting indicator (as well as a more appropriate objective) of support measures. The definition of the indicators is therefore closely linked with a policy goal, objective and/or target. The results should be measured against them. 
The latter also depends on other external factors such as local education facilities (that train creative professionals and artists), cultural amenities (to make the city attractive to creative people or to stimulate cultural participation), quality of life, access to technological infrastructure, and other socio-economic conditions. The evaluation methodology should consider whether the policy has actually encouraged new behaviour (additionality), separate the 'net' from the 'gross' effects (displacement and substitution), calculate multiplier effects, and take into account the counterfactual (what would have occurred in the absence of the policy). Last but not least, the implementation of the raster should be accompanied by an evaluation culture also reflected in an adequate resource allocation to collect and assess data.

The raster should be used as a tool to assess which policies support the creative potential of cities and regions, and to select the best measures to develop a creative economy. The ultimate purpose would be to develop smart specialisation strategies focussing on CCIs. Those are identified as a priority sector by the Smart Specialisation Strategy Platform set up last year by the European Commission to help regions implement their smart strategies for development and growth.

Nevertheless, the proposed set of indicators is the very first step towards the definition of an appropriate evaluation of CCI policies at the local level. Future research should explore how indicators covering social and environmental aspects of local CCI policies could be integrated in the benchmarking raster. Its potential contribution to smart specialisation strategies based on CCIs should also be tested at some point. At a more operational level, it should be investigated how the benchmarking raster could be used in the framework of comprehensive evaluation strategies and methods, and how it could be introduced in local administrations facing resource constraints and having little experience with the evaluation of public policies for cultural and creative enterprises.

\section{References}

Allin P., 2000. The development of comparable European cultural statistics. Cultural Trends, 37: 66-75.
BaKHSH H., McVittie E. \& Simmie J., 2008. Creating innovation. Do the creative industries support innovation in the wider economy? NESTA, London.

BONET L., 2004. Reflexiones a propósito de indicadores y estadísticas culturales. Gestion Cultural, 7, April.

Centre for Strategy and Evaluation Services (CSES), 2002. Benchmarking of business incubators (Final report). European Commission, DG Enterprise, Brussels.

Centre for Strategy and Evaluation Services (CSES), 2010. Study on the contribution of culture to local and regional development - evidence from the Structural Funds. European Commission, DG Education and Culture, Brussels.

Csikszentminalyi M., 1996. Creativity: Flow and the psychology of discovery and invention. HarperCollins, New York.

Cunningham P., Robson D. \& Neves E., 2008. Mapping of innovation support measures. Pro Inno Europe - Inno Learning Platform, Brussels.

Europaid evaluation methodology. Available at: http:// ec.europa.eu/ europeaid/ evaluation/ methodology/ methods/ mth_ind_en.htm

European Commission, 2000. Cultural statistics in the EU: Final report of the LEG. Eurostat Working Paper, Brussels.

European Commission, 2010. Green paper on unlocking the potential of cultural and creative industries. Brussels.

FloridA R., 2002. The rise of the Creative Class. Basic Books, New York.

Florida R., 2006. The flight of the Creative Class. HarperCollins, New York.

FoORD J., 2008. Strategies for creative industries: an international review. Creative Industries Journal, 1(2): 91-113.

Gertler M.S., Florida R., Gates G. \& Vinodrai T., 2002. Competing on creativity: Placing Ontario's cities in North American context. Report prepared for the Ontario Ministry of Enterprise Opportunity and Innovation and the Institute for Competitiveness and Prosperity.

GLADE W., 2003. Conceptualisation and measurement problems in developing cross-national cultural indicators: A methodological odyssey. Paper prepared for UNESCO/ CONACULTA International Seminar on Cultural Indicators, Centro Nacional de las Artes, Mexico, 7-9 May.

GouiEDo L., 1993. Proposals for a set of cultural indicators. Statistical Journal of the United Nations, 10: 227-289.

International Federation of Arts Councils and Culture Agencies (IFACCA), 2002. International comparisons of arts participation data. Sydney.

International Federation of Arts Councils and Culture Agencies (IFACCA), 2004a. Making crosscountry comparisons of cultural statistics: Problems and solutions. Working paper, Sydney.

International Federation of Arts Councils and Culture Agencies (IFACCA), 2004b. Statistical indicators for arts policy: Discussion paper. Sydney.

KEA, 2006. The economy of culture in Europe. European Commission, DG Education and Culture, Brussels.

KEA, 2009. Study on the contribution of culture to creativity. European Commission, DG Education and Culture, Brussels.

KEA, 2010. Study on promoting investment in the cultural and creative sector: Financing needs, trends and opportunities. Commissioned by Nantes Métropole, Brussels.

KoткIN J., 2005. Urban legends. The New Republic, 23 May.

LIEVESLEY D., 2002. Statistics in the wake of challenges posed by cultural diversity in a globalisation context. International 
Symposium on Culture Statistics, Montreal, October 21-23.

Listening and learning: Community indicator profiles of Knight Foundation communities and the nation, 2001. John S. and James L. Knight Foundation.

Malanga S., 2004. The curse of the creative class. City Journal, 14(1): 36-45.

MANNINEN A., 2002. Towards harmonised cultural statistics: Experiences from recent and ongoing projects in Europe. International Symposium on Culture Statistics, Montreal, October 21-23.

McCANN E., 2007. Inequality and politics in the creative cityregion: Questions of liveability and state strategy. International Journal of Urban and Regional Research, 31: 188-196.

OECD, 2010. DAC guidelines and reference series - quality standards for development evaluation. OECD.

Porter M.E., 1998. Clusters and the new economics of competition. Harvard Business Review, 76 (6): 77-90.
Pratt A.C. \& JefFCutt P. (eds), 2009. Creativity, innovation and the cultural economy. Routledge, London.

Rushton M., 2006. The creative class and urban economic growth revisited. Paper prepared for the 14th International Conference of the Association for Cultural Economics International, Vienna, 6-9 July.

SANDS G. \& ReESE L.A., 2008. Cultivating the creative class: and what about Nanaimo? Economic Development Quarterly, 22(1): 8-23.

Smart Specialisation Platform, 2011. RIS 3 Guide (draft). European Commission, Brussels.

Throsby C.D., 2001. Economics and culture. Cambridge University Press, Cambridge.

UNCTAD, 2008. Creative economy report 2008. UNCTAD.

UNCTAD, 2010. Creative economy report 2010. UNCTAD.

Utrecht School of the Arts, 2010. Study on the entrepreneurial dimension of cultural and creative industries. European Commission, DG Education and Culture, Brussels. 